\title{
Sin billete de retorno. Aproximaciones a las trayectorias laborales y vitales de las españolas exiliadas en Francia
}

\author{
Rocío Negrete Peña ${ }^{1}$
}

Recibido: 20 de diciembre de 2019 / Aceptado: 21 de abril de 2021

Resumen. El presente artículo tiene por objeto trazar las trayectorias de mujeres exiliadas en Francia a partir del análisis de los mecanismos de inscripción del colectivo exiliado y sus asignaciones desde una perspectiva de género. Al internamiento en campos y refugios le siguieron los intentos de repatriación o su utilización como contribución a la economía nacional de la Francia en guerra y durante la Ocupación. En la posguerra, el beneficio del estatus de refugiado junto a la renuncia a regresar a España en un medio plazo implicaba la consecuente necesidad de integrarse en la sociedad francesa. Con el fin de reconstruir estas trayectorias vitales y laborales, serán de gran utilidad tanto la documentación administrativa francesa o de organismos de ayuda como las fuentes testimoniales.

Palabras clave: exilio republicano, mano de obra, agencia femenina, resistencias, integración.

\section{[en] With no ticket of return. Approaches to the work and life trajectories of Spanish women in exile in France}

\begin{abstract}
The purpose of this article is to trace the trajectories of exiled republican women in France based on an analysis of the mechanisms by which the exiled group is insered in the French society and its assignments from a gender perspective. Internment in camps and shelters was followed by attempts to repatriate them or use them as a contribution to the national economy in wartime and during the Occupation. In the post-war period, the benefit of refugee status as well as the refusal to return to Spain in the medium term implied the consequent need to integrate into French society. In order to reconstruct these life and work trajectories, both French administrative or aid agency documentation and testimonial sources will be very useful to analyse.
\end{abstract}

Keywords: Republican exile, workforce, women's agency, resistances, integration.

Sumario. Introducción. 1. Agencias y resistencias de las exiliadas políticas en los refugios y campos de internamiento. 2. Actividades y trabajos de las republicanas en Francia. Más allá del espectro de la domesticidad. 3. Españolas en la tormenta de otra guerra. Supervivencia y vida cotidiana. 4. Conclusiones. 5. Referencias bibliográficas.

Cómo citar: Negrete Peña, R. (2021). Sin billete de retorno. Aproximaciones a las trayectorias laborales y vitales de las españolas exiliadas en Francia. Cuadernos de Historia Contemporánea, Vol. 43, 305-324.

1 UNED/Université Bordeaux-Montagne

E-mail: rnegrete@geo.uned.es 


\section{Introducción}

El exilio republicano se caracterizó por una profunda heterogeneidad, con diferentes lugares de origen y de acogida, fechas, profesiones, niveles socio-económico, estudios, edades o familia. Como apuntó Geneviève Dreyfus Armand ${ }^{2}$, el exilio que llegó a Francia (donde no hubo una selección por parte del país o de las autoridades republicanas) es un fiel reflejo de la sociedad española de su época. El género no es sino otro elemento diferencial que marcó el destino de cada exiliado y exiliada. Es por ello por lo que el tratamiento tradicional del exilio femenino como "acompañantes"3 debe ser urgentemente revisado.

“¿Qué es lo que les empujó a exiliarse? ¿La historia de las mujeres puede presentar interés cuando decidimos interrogar los testigos alejados de los grandes centros de acción y de decisión?"4. María José Nadal formuló estas dos cuestiones en un temprano artículo sobre las mujeres españolas exiliadas tras la Guerra de España, dando por hecho que estas mujeres, por un lado, no formaban parte de grandes centros de acción y decisión y, por consiguiente, que su testimonio no sería tan interesante. El o la refugiada política son, por definición, víctimas de un conflicto político que son acogidas en otro país y cuyo estatus jurídico ha sido progresivamente regulado a lo largo del siglo $\mathrm{XX}^{5}$. En el caso del exilio español, este estatus no fue efectivo hasta 1945, por lo que la denominación habitual de los y las exiliadas como "refugiés", incluso por el lenguaje administrativo de la década de 1930, es, además de incorrecto desde el punto de vista del derecho internacional, una muestra de una voluntad de sometimiento al Estado que les acogía. Maëlle Maugendre ${ }^{6}$ ha estudiado cómo, aplicando criterios de género, el tratamiento dispensado por las autoridades francesas hacia las refugiadas republicanas estuvo profundamente influenciado por imágenes sociales y estereotipos como "la miliciana", "la mujer de mala costumbre" o "la víctima inocente". Mas, ¿cuánto hay de cierto en estas asignaciones?, ¿y en qué medida los estudios sobre las mujeres en el exilio republicano son deudores de ellas?

Reconocer la capacidad de las mujeres exiliadas para acarrear con su propio destino y construirse unas trayectorias vitales y laborales diversas es una de las tareas que la historiografía del exilio republicano, tras las celebraciones sociales y académicas de su 80 aniversario ${ }^{7}$, sigue teniendo pendientes. Como destacó Ana Aguado,

Las experiencias de las mujeres republicanas en el exilio muestran, desde una Memoria de la Guerra Civil e identidades femeninas antifranquistas, una enorme pluralidad política, la necesidad de cuestionar estereotipos masculinos de heroísmo

2 Dreyfus Armand, Geneviève : L'exil des républicains espagnols en France: de la Guerre civile à la mort de Franco, Paris, Albin Michel, 1999.

3 Moreno Seco, Mónica: «Las exiliadas, de acompañantes a protagonistas », Ayer, 81, 2011, pp. $265-281$.

$4 \quad$ Nadal, Marie-José : «Femmes de l'exil espagnol. Formation idéologique et action politique des femmes du peuple ayant choisi de s'exiler en France en 1939 », Matériaux pour l'histoire de notre temps, 15-1, 1989, pp. 28-37,

5 Groppo, Bruno : «La notion de réfugié au XXe siècle », Exils et migrations ibériques au XXe siècle, 2-7, 1999, pp. $165-178$.

$6 \quad$ Maugendre, Maëlle : « Les réfugiées espagnoles en France (1939 - 1942) : des femmes entre assujettissements et résistances » Thèse de doctorat, Université de Toulouse Mirail, Toulouse, 2013.

7 El 16 de noviembre de 2018, por acuerdo del Consejo de Ministros se creó una comisión interministerial para la celebración del 80 aniversario del exilio republicano. Entre sus manifestaciones, para el tema que nos ocupa, destaca el Congreso Internacional "Mujeres en el exilio republicano de 1939", celebrado del 16 al 18 de octubre en Madrid. 
y de resistencia, desde la puesta en valor de las relaciones entre mujeres, guerra, antifascismo y resistencia ${ }^{8}$.

Siguiendo esta línea de investigación, el presente artículo tiene por objeto trazar las trayectorias de mujeres exiliadas en Francia a partir del análisis de los mecanismos de inscripción del colectivo exiliado y sus asignaciones desde una perspectiva de género. La imbricación de lo político y lo social con lo económico se torna necesario para reconstruir dichas experiencias. Sus destinos estuvieron marcados directamente por la derrota republicana en la guerra y por su posicionamiento -activo o pasivocomo rojas, en el marco de las reflexiones emanadas desde los estudios de género y de la subalternidad a partir de la noción de "agencia". Las fuentes testimoniales orales y escritas recogen una pluralidad de experiencias propias del ámbito cotidiano y privado que son menos visibles en otro tipo de fuentes. En efecto, las relaciones de poder y de subordinación dejan una profunda impronta en la producción documental, de modo que la enunciación del relato por las mismas protagonistas permite extraer nuevos datos y puntos de vista ${ }^{10}$. Por ello, nos basaremos en varias memorias y testimonios de mujeres exiliadas en diálogo con otro tipo de documentación administrativa extraída de los Archivos Departamentales de la Gironda, como ejemplo de agente de poder y de control de la población española exilada en el país ${ }^{11}$, o del Fondos del Ministerio de Emigración del Gobierno de la República en el exilio, donde las mujeres también llegaron a ser protagonistas y productoras de la documentación.

En este artículo se explorarán estos destinos en tres escenarios diferentes en los que la mujer exiliada fue protagonista. En primer lugar, los refugios y campos de concentración, con relación a las formas de resistencias al retorno forzado a España y a ser reconocidas como agentes activos. A continuación, el acceso a un trabajo, más o menos remunerado, como etapa clave para este reconocimiento y para salir de la tutela directa de las autoridades francesas en sus destinos. Finalmente, nos focalizaremos en los mecanismos de inserción y estrategias de supervivencia en la Francia ocupada y en el nuevo contexto que se dibuja a partir de 1945.

\section{Agencias y resistencias de las exiliadas políticas en los refugios y campos de concentración}

En realidad, entre todas nuestras compañeras de reclusión, las que se arriesgaban a la pena de muerte yendo al país no eran muchas. Pero una vez en él se les iba a plantear otro problema menor: el de ganarse la vida. No importaba que el marido se quedase en Francia o que volviese a España, donde sería juzgado y, en el mejor de los supuestos, encarcelado; en ambos casos, las perspectivas de la familia eran

8 Aguado, Ana: « Memoria de la Guerra Civil e identidades femeninas antifranquistas », Amnis. Revue de civilisation contemporaine Europes/Amériques, 2, 2011, pp. 7-8.

9 Vázquez Laba, Vanesa; Rísquez Buonaffina, Mariela; Perazzolo, Romina y Giménez Mercado, Claudia: «Resistencias desde los márgenes: la experiencia migratoria de las mujeres como forma de agencia social», Revista de estudios de género: La ventana, 5-40, 2014, pp. 59-87.

10 Un ejemplo de su utilización en Martínez Martínez, Alba: « Las mujeres recuerdan. Género y memoria sobre el exilio republicano en Francia (1939-1978) », Arenal: Revista de historia de mujeres, 26-2, 2019, pp. 367-398.

11 La elección de estos archivos departamentales, entre otros con un tipo de documentación muy similar, se debe al amplio conocimiento de los mismos gracias al trabajo desarrollado durante el curso 2018-2019 en la Université Bordeaux-Montagne, donde realizo el Doctorado en cotutela. 
desastrosas. La mayor parte de aquellas mujeres no había trabajado nunca, fuera de las faenas caseras, no tenían oficio ni beneficio; las que habían dejado algunos bienes sabían que fueron confiscados. En el campo de concentración, a falta de otros alimentos, no carecíamos de pan. Tampoco de incordios ni de vejaciones, pero en tierra extraña resultaban menos humillantes, herían menos que en el suelo natal, en un pueblo o en un barrio, donde todo el mundo se conoce y hay una reputación familiar que defender. Por eso algunas aguantaron hasta no poder más ${ }^{12}$.

Con estas palabras de Francisca Muñoz Alday se introduce uno de los aspectos que la historiografía de género viene trabajando: el del papel político activo de las mujeres exiliadas, más allá del de las principales figuras que suelen ser evocadas. En los últimos años la historiografía ha puesto de relieve cómo la represión franquista incidió de una forma particular en las mujeres, y que, además, esta represión podía ser física, política o económica ${ }^{13}$. No obstante, las amenazas que las exiliadas en suelo francés temían poder recibir si regresaban a España fue menor, en principio, que en el caso de los hombres. De hecho, la bicategorización que la ideología nacional-católica asignaba a las mujeres entre las "mujeres perdidas" o "rojas" y la "buena mujer"14, y los medios dedicados para eliminar -si no convertir a las primeras en las segundas-, quedaba reflejada en el lenguaje y tratamiento que las autoridades franquistas pusieron en marcha para motivar el retorno de "aquellas que no tenían nada que temer" a España. Así lo recoge Silvia Mistral en su Diario de una refugiada española:

España victoriosa y grande, salvada para la paz y el progreso, inicia su era de apogeo en todos los órdenes (...) Vosotras, mujeres españolas, volveréis a vuestros hogares y en ellos os sentiréis felices, porque aunque halléis vuestras casas en ruinas sentiréis la alegría, la inmensa alegría de la paz, de la reconstrucción. Se os dan toda clase de facilidades y podéis dirigiros a donde os interese u os plazca ${ }^{15}$.

Por ello, una de las tareas más importantes que las mujeres más politizadas emprendieron en los campos y refugios fue el de no dejar que sus compañeras perdieran la esperanza y aceptasen retornar a España, además de intentar calmar, con sus pocos medios, las necesidades más inmediatas y "normalizar la vida". Como relata Carmen Roure Canot, "nuestro trabajo era... tranquilizar a las compañeras, ver si podíamos tener contacto y escribir a los compañeros (...) después que la leche se distribuyera bien a los niños; que no hubiera ningún lío... a ver si se podía dar clase a los niños"16.

El aliento de estas mujeres fue clave para la resistencia ante los esfuerzos repetidos de las autoridades francesas de fomentar su repatriación con el fin de vaciar los campos y refugios, hasta el punto de llevar a cabo retornos forzados ${ }^{17}$. Las autori-

12 Muñoz Alday, Francisca: Memorias del exilio, Barcelona, Viena, 2007, pp. 90-91.

13 Murillo Aced, Irene: En defensa de mi hogar y mi pan: estrategias femeninas de resistencia civil y cotidiana en la Zaragoza de posguerra, 1936-1945, Universidad de Zaragoza, 2013.

14 Sánchez Sánchez, Pura: Individuas de dudosa moral: la represión de las mujeres en Andalucía (1936-1958), Barcelona, Crítica, 2009.

15 Mistral, Silvia: Éxodo. Diario de una refugiada española, Madrid, Diario Publico, 2011, p. 171.

16 «Entrevista a Carmen Roura Canot», Archivo Histórico Nacional, sección Guerra Civil (Salamanca), Fuentes Orales México. En Carmen de la Guardia: "Maestras republicanas españolas en el exilio" en Sánchez de Madariaga, Elena (coord.): Las maestras de la República, Madrid, Los Libros de la Catarata, 2012, p. 207.

17 Alted Vigil, Alicia: « El paso de frontera como ruptura en las mujeres exiliadas », en Almela Boix, Margarita; García Lorenzo, María Magdalena; Guzmán García, Helena; Sanfilippo, Marina (coords.): Mujeres en la fron- 
dades francesas mandataban en sus circulares "la aceleración del ritmo de retornos voluntarios" y se indicaba que no se ejerciera "ninguna coerción sobre una decisión que debe seguir siendo libre". Paradójicamente, al mismo tiempo se apuntaba que, debido a los intereses nacionales y, en especial de las finanzas públicas, se deben "orientar las dudas hacia la partida (sic)"18.

Las prefecturas de los distintos departamentos recogen estas resistencias y la importancia del apoyo de la comunidad en las mismas, como el caso de Carmen Gonzáles (sic) y Felisa Torres, que, figurando en la lista de pasajeras de un convoy con dirección a España desde Talence (Gironda), no lo tomaron, "la primera diciéndose enferma y la segunda estando bajo la influencia de algunas compatriotas del campo". Además, "la llamada Gonzáles, no solamente se paseaba por el campo burlándose del vigilante, sino que se ocupó de lavar su ropa. Así que no estaba enferma. Estas actitudes (...) perjudican la disciplina del campo, el mantenimiento de la autoridad y comprometen completamente las posibles partidas"19. En la continuación de este informe se denuncia también la actitud de la persona "inconveniente, arrogante y amenazante hacia el personal del centro" de Incarnation (sic) Rodríguez, viuda de 60 años, que "ha contribuido a sembrar el desorden" e "influencia a sus compatriotas para no retornar a España"; así como la de su hija mayor Irma, de 22 años, la cual "últimamente, un domingo por la tarde en una barraca del campo, arengó a sus compatriotas recomendándoles que no soliciten su regreso a España" 20 .

El relato que hacen estas mujeres constituye una fuente clave para reconstruir las vivencias en el exilio en clave de género, aunque teniendo siempre en cuenta sus dificultades metodológicas. Así, junto a las memorias editadas -0 las que se custodian en archivos familiares-, los archivos de las prefecturas o de diversos organismos de ayuda conservan pequeños testimonios en los que, en forma de súplica, las mujeres exiliadas se dirigían a sus intermediarios detallando su situación. Vemos, en este sentido, como varias de estas fuentes recogen un relato según el cual algunas exiliadas solicitaban permanecer en suelo francés argumentando no poder retornar a España por razones políticas, junto con un segundo grupo, no obstante más numeroso, que se inserta en un modelo de exilio "familiar" y un tercero que acepta regresar. Así lo recoge un informe de la situación de las 27 refugiadas en el centro de acogida de Blaye (Gironda):

de este examen resulta que la mayoría de las refugiadas tiene a su marido, o los padres que las pueden ayudar en Francia, y han declarado que no pueden marcharse si no es con ellos. Tres o cuatro son buscadas en España por la policía política y no pueden regresar a su país por miedo a las represalias. Solamente cuatro refugiadas no tienen ninguna relación en Francia y no tendrían nada que temer en el régimen actual español ${ }^{21}$.

tera, Madrid, Universidad Nacional de Educación a Distancia, 2013, pp. 39-52.

18 «Circulaire du Ministre de l'Intérieur à Messiers les Préfets. Paris, le 1er Août 1939 » : Archives Départementales de la Gironde (33), Etats numériques de réfugiés espagnols hébergés dans les centres du département et transferts (1936-1939) : 4 M 514.

19 «Le Commissaire de Police de Talence à Monsieur le Préfet de la Gironde. Talence, le 10 août 1939 ». Archives Départementales de la Gironde (33), Etats numériques de réfugiés espagnols hébergés dans les centres du département et transferts (1936-1939) : 4 M 514.

20 Ibid.

21 La cursiva es mía. « Le sous-préfet de Blaye à Monsieur le Préfet de la Gironde. Blaye, le 12 aout 1939 ». Archives Départementales de la Gironde (33), Etats numériques de réfugiés espagnols hébergés dans les centres du département et transferts (1936-1939) : 4 M 514. 
La refugiada Eleonor Madrenas escribió desde Francia una solicitud a la CTARE (Comité Técnico de Ayuda a los Refugiados Españoles) para que intercediese a favor de su evacuación hacia México. Estas líneas de su carta que recoge Guadalupe Adámez Castro revelan un perfil de mujer que "bajo ningún concepto puede volver a España en tanto el fascismo detente el poder" y que, además, se muestra como trabajadora e instruida, y, "activa y seria" de cara a reconstruir una vida en el exilio:

Mis intenciones son las de evacuar de territorio francés y como por mis actividades ideológicas estoy comprendida entre los elementos que bajo ningún concepto puede volver a España en tanto el fascismo detente el poder, no dudo tendrán en cuenta mi caso lo antes posible (...) Yo deseo trabajar. Soy activa y seria. Tengo 28 años. Poseo fuertes nociones de francés. Mi profesión es la de taquimecanógrafa. Conozco a la perfección los trabajos generales de organización y oficina ${ }^{22}$.

Así, una profundización en la historia del exilio republicano en clave de género deja ver varias grietas en el retrato tradicional del hombre militante y la mujer recluida en el hogar. Elisabeth Jelin sostenía en relación con el género de las memorias que, "dado el sistema de género en las relaciones familiares, además de ser víctimas 'directas', las mujeres fueron básica y mayoritariamente víctimas 'indirectas', y este es el rol en el que se visualiza más a menudo: como familiares de víctimas" ${ }^{23}$. Por lo tanto, la actualización del término de "víctima", o de "acompañante" se torna necesaria para evidenciar estas trayectorias diversas, amén de otros terrenos y situaciones menos exploradas a las que las mujeres exiliadas también hicieron frente. La intervención activa de las mujeres ante lo que ellas consideraban una injusticia es también evocada por Anita Pujol, cuando recuerda una escena ocurrida en el campo de Argelès en marzo de 1941. Ante la orden de que los antiguos brigadistas internacionales allí internados fueran enviados a África, los españoles del campo tomaron la decisión de apoyar su resistencia, y "lo más fuerte es que esta iniciativa fue tomada por las mujeres. Los hombres dudaban, no se atrevían, temían las consecuencias del levantamiento (...) Fue [la parte de] el campo de mujeres que se levantó" 24 .

La agencia de las mujeres exiliadas no debe entenderse, por lo tanto, solamente como la militancia política, sino que su actividad impregnaba todos los aspectos de la vida cotidiana y, sin ella, no se habría podido garantizar la supervivencia en el exilio. Hablamos así del "courage anonyme au quotidien" 25 donde el compromiso y la acción política jugaron un papel determinante en la vida de las exiliadas, a pesar de que estuvieron en gran parte imbricados e insertos en las experiencias del espacio privado o "doméstico".

22 «Petición de Eleonor Madrenas para José Puche (CTARE), 23 de junio de 1939». Citado en Adámez Castro, Guadalupe: Gritos de papel: Las cartas de súplica del exilio español, Granada, Comares, 2017.

23 Jelin, Elisabeth: Los trabajos de la memoria, Madrid, Siglo XXI de España Editores, 2002, p. 104.

24 Montseny, Federica : Révolutionnaires, réfugiés et résistants : Témoignage des républicains espagnols en France, Editions CNT-Région parisienne, 2018, p. 73.

25 Berenguer, Sara : Femmes d'Espagne en lutte: Le courage anonyme au quotidien, de la guerre civile à l'exil, Lyon, Atelier de création libertaire, 2011. 


\section{Actividades y trabajos de las republicanas en Francia. Más allá del espectro de la domesticidad}

Si la labor de las mujeres en los refugios y campos fue providencial, en el marco familiar y en la economía doméstica, ellas desempeñaron un rol imprescindible y que trasciende más allá del ámbito de lo privado. Pues, si como también analizó Pilar Domíngue $z^{26}$ se puede dividir el exilio femenino en dos grandes grupos -las mujeres que decidieron exiliarse solas huyendo de la guerra o la represión, y las que lo hicieron junto a sus familias-, estas categorías se reconfiguran al pasar la frontera $y$, sobre todo, al rechazar el retorno a España y al construir una nueva vida en el exilio.

La separación de familias constituye, de hecho, una de las primeras decisiones políticas tomada en clave de género por las autoridades francesas hacia los y las exiliadas españolas. La repartición en campos y refugios en función de categorías de género significaría para los hombres y mujeres -y los niños- vivencias diferentes, pero, sobre todo, el objetivo primero de la reagrupación familiar como condicionante de toda decisión o movimiento. Pero, además, tanto en los campos como en los refugios, se sistematizó el trabajo como estructuración misma del internamiento ${ }^{27}$. La voluntad de las mujeres exiliadas de hacer más habitables estos espacios, dentro de las malas condiciones, constituye una forma, por un lado, de ser útiles y de mantenerse ocupadas y, por otro, de tomar las riendas de su propio destino. Junto a la ayuda mutua y las redes de resistencia colectiva que establecieron las mujeres con sus compañeras de barraca o habitación ${ }^{28}$, se configuraron dinámicas domésticas de mantenimiento del espacio con equipos de limpieza o de cocina. María Magda Sans especificaba cómo, en una antigua fábrica de armamento reconvertida en albergue cerca de Rennes,

ante la realidad que estábamos viviendo, creímos conveniente organizarnos para que nuestra estancia en este lugar fuera lo menos dolorosa posible. La comida que nos habían dado, recién llegados, era bastante desagradable. Organizamos grupos rotativos que se ocuparan de la cocina y se organizaron en el interior de cada barraca formas de convivencia más agradables, tales como recitación de poesías, cantos, representaciones teatrales, bailables, etc., etc. ${ }^{29}$.

Además de estos equipos o "brigadas", Luisa Carnés hablaba de "habilidades", por ejemplo, hacerse amiga de la cocinera o presentarse como "voluntaria" para secar la vajilla con el fin de tener acceso a la cocina ${ }^{30}$. Igualmente, los refugios y los campos se convirtieron en el marco donde tuvo lugar otro tipo de actividades de carácter cultural y profesional como clases o talleres que contribuían a pasar el tiempo

26 Domínguez Prats, Pilar: De ciudadanas a exiliadas: un estudio sobre las republicanas españolas en México, Madrid, Cinca, 2009.

27 Tuban, Grégory : Camps d'étrangers : le contrôle des réfugiés venus d'Espagne (1939-1944), Paris, Nouveau Monde éditions, 2018.

28 Un proceso similar se desarrollaría con la formación de "familias" entre las mujeres deportadas que detalla Neus Català en su testimonio de su resistencia y su deportación. Català, Neus : De la resistencia y la deportación. 50 testimonios de mujeres españolas, Barcelona, Adgena, 1984.

29 En Bravo, Blanca (coord.): Nuevas Raíces: Testimonios de Mujeres Españolas en el Exilio, México, Editorial Joaquín Mortiz, 1993. p. 248.

30 Carnés, Luisa: De Barcelona a la Bretaña francesa. Memorias, Biblioteca del exilio, Barcelona, Renacimiento, 2014, pp. 227-228. 
y evitar la ociosidad. Especialmente las mujeres que habían acompañado colonias de niños al cruzar la frontera tuvieron un papel imprescindible, si bien en un marco tradicionalmente femenino como la educación y los cuidados, que continuaría en los campos $^{31}$ y refugios. La improvisación de escuelas por parte de mujeres que habían ejercido como maestras en España es quizás uno de los primeros intentos de "emancipación" que pronto se darían en el plano laboral.

La presión para vaciar los campos y refugios por parte de las autoridades, junto a la negativa de regresar a España y la dificultad de conseguir embarcar a México motivó una búsqueda de un trabajo que les permitiese, además de salir del internamiento (como primer paso para la reunificación familiar), la obtención de un jornal con el que salir adelante. La sucesión de decretos y circulares ministeriales van orientando la exigencia de un empleo remunerado para permitir la salida del campo o refugio (que a su vez se van cerrando o se van reconvirtiendo para acoger a nuevos refugiados del Norte de Francia o Bélgica) y la reunificación en torno al "cabeza de familia", de forma que Maëlle Maugendre habla de un "proceso de emancipación controlado" 32 . Mas el aislamiento, la desconfianza inicial de la población francesa hacia los "indeseables" refugiados, la protección de la mano de obra local y la adaptación económica a tiempos de guerra desde septiembre de 1939 dificultaron muchas veces este acceso al mercado de trabajo, a pesar de la férrea voluntad de las exiliadas españolas por encontrar dicho empleo remunerado "en cualquier cosa".

Sin embargo, la mano de obra "barata y eficiente ${ }^{33}$ " que representaban las mujeres exiliadas no tardó en resultar atractiva para, primero la economía local y, luego, la economía nacional. Francisca Merchán recordaba cómo las españolas en Francia “trabajaron unas como campesinas, otras como 'bonnes' o chachas, otras, las menos numerosas, en alguna fábrica y en la costura, $\mathrm{y}$, finalmente, otras, muy pocas, pudieron acompañar a los maridos a otros lugares" ${ }^{34}$. Pero a pesar de encontrar estas evocaciones sobre el papel, no solamente activo, sino necesario para la supervivencia económica del núcleo familiar de las mujeres exiliadas, esta realidad no ha merecido aún un estudio específico para el caso francés ${ }^{35}$.

Las mujeres exiliadas demostraron una actitud proactiva buscando "faena" en los pueblos donde se encontraban diseminadas, la mayor parte de las veces sin ningún tipo de regulación o incluso sin salario. La joven Blanca Bravo buscó su primer empleo en un hotel regentado por un "señor español, viejo residente en Francia":

31 También en el campo de Argelès: "habían reservado una barraca sólo para niños. A partir de los cinco o seis años los separaban de las madres. Venían a verlas, un ratito a fines de la tarde y luego regresaban a su "pensión". Aquella era seguramente una buena decisión, comían un poco mejor y algunos maestros les daban clases con los recursos de que disponían”. En Oliva Berenguer, Remedios: Éxodo: Del campo de Argelès a la maternidad de Elna, Barcelona, Viena, 2006, p. 57.

32 Maugendre, Maëlle : «Les réfugiées espagnoles en France (1939 - 1942) : ... » op. cit., pp. 455 y ss.

33 Testimonio de Carmen Prieto Escobar. En Rodrigo, Antonina: Mujer y exilio, 1939, Madrid, Compañía Literaria, 1999, p. 277.

34 Merchán Tejero, Francisca (dir.): Memorias del olvido : la contribución de los republicanos españoles a la resistencia y a la liberación de Francia, Federación de Asociaciones y Centros de Emigrantes Españoles en Francia, 1996, p. 162.

35 Para el caso de México, Domínguez Prats, Pilar: De ciudadanas a exiliadas, op. cit ; Röwekamp, Marion: "Myth of Equality? Professional Life of Spanish Republican Women in Exile in Mexico », iMex Revista. México Interdisciplinario, 5-3, 2013, pp. 86-108, y de Hoyos Puente, Jorge: « Las mujeres exiliadas con la configuración de la identidad cultural y política de los refugiados españoles en México », Ubi sunt? Revista de Historia, 0-27, 2012, pp. 28-40. 
Me ofrecía a desempeñar cualquier trabajo aunque fuera pesado. Creo que, en el fondo, le inspiré lástima y aceptó que empezara a trabajar al día siguiente, sin contrato y sólo ganando unos miserables francos y las propinas (...)

Comprendí que me había convertido en una criada. Después de todo era un trabajo durísimo, pero honesto. Llegaba a mi casa a las 9 de la noche con el cuerpo molido, pero entraba con la cara sonriente, y cuando mi madre me preguntaba si podría aguantar el cansancio yo le respondía que sí, porque era joven y superaría aquello y mucho más. A los quince días la señora del dueño, de malas maneras, me echó a la calle injustamente (...)

Mi compañera, que tenía unos veinte años, me consoló haciéndome ver que aquel trabajo no era propio para mí. Sí, sí tienes toda la razón, pero en mi casa no entran más francos que los que yo gano. Si mi hermana Pepina y su marido ganaran algo, bueno sería pero por ahora no han encontrado trabajo, y con esto nos vamos a quedar sin $\operatorname{nada}^{36}$.

El sector agrícola y ganadero, donde trabajó una parte importante del colectivo exiliado -sobre todo en la vendimia, la recogida de productos como la remolacha, el talado de madera o las granjas-, se caracterizó por sus duras condiciones y por emplear a familias enteras. Fueron frecuentes, por lo tanto, las solicitudes de trabajo para "su mujer, también obrera agrícola" 37 o en las que se ofrecía, ante la falta de mano de obra agrícola, a su familia ${ }^{38}$. Pero también los abusos y malas condiciones fueron en ocasiones contestados, a pesar de la situación de subordinación en la que claramente se encontraban. Por ejemplo, tres familias compuestas por 4 hombres, 5 mujeres y cinco niños llegaron el 14 de abril de 1940 a Sadirac (Gironda) para trabajar de agricultores. En una carta escrita por el propietario de la explotación agrícola a la que fueron dirigidos, este afirmaba que "había pedido a la dirección del servicio de refugiados, a la prefectura de Amiens, que ya había proporcionado agricultores para la vendimia, que le enviara de nuevo dos familias españolas". Sin embargo, el propietario reclamaba que recogió "en la estación de Créon 14 españoles, que no quieren trabajar, dicen que no son agricultores y quieren dirigirse a Toulouse ${ }^{39}$."

La huella de esta pequeña rebelión muestra el seguimiento que las autoridades francesas iban haciendo de la inserción de la mano de obra española, también de las mujeres, en este progresivo interés en su aprovechamiento ${ }^{40}$. Y, especialmente, en el contexto de la guerra en Francia y debido a la movilización de los hombres y a la separación familiar, la relevancia del trabajo de las mujeres para la economía familiar alteró los estándares tradicionales de la división sexual del trabajo. Pilar Domínguez Prats ha denominado la actividad laboral precaria y urgente de las exiliadas en Fran-

36 Bravo, Blanca (coord.): Nuevas Raices... op. cit, pp. 23-24.

37 « Dossier de José Urcelay ». Archives Départementales de la Gironde (33), Correspondance et rapports divers - 4 M 512 (1939-1940)

38 «Dossier de Vicente Serra ». Archives Départementales de la Gironde (33), Correspondance et rapports divers - 4 M 512 (1939-1940)

39 « Lettre de L. Guyot de Villeneuve à M. le Préfet de la Gironde. Sadirac, le 15 avril 1940 ». Archives Départementales de la Gironde (33), Correspondance et rapports divers - 4 M 512 (1939-1940)

40 Negrete Peña, Rocío: « Cuando las exiliadas dejaron de ser des bouches inutiles. Españolas en Francia e inserción laboral: 1939-1940 », en Moreno Seco, Mónica; Fernández-Sirvent, Rafael y Gutiérrez Lloret, Rosa Ana (coords.): Del siglo XIX al XXI. Tendencias y debates. XIV Congreso Asociación de Historia Contemporánea, 20-22 septiembre 2018, Alicante, 2019, pp. 1454-1466. 
cia como una "época de pruebas" de lo que sería su inserción laboral para aquellas que consiguiesen reemigrar a México. Esto queda ilustrado en el testimonio de Pilar Vallés, que a su vez evoca la importancia del trabajo femenino, no solamente para la economía familiar "de supervivencia", sino para garantizar la "estabilidad" mínima de esta, facilitando la actividad política del "cabeza de familia":

Mi madre se puso a coser, ya sabes que todas las españolas de antes sabían hacer algo de costura... ella lo hacía muy bien (...) Total, que al final pusimos un negocio de camisas y no nos fue tan mal. Ya empezamos poco a poco a comprar máquinas de coser y trabajaban allí varios españoles... Pero entonces, mi padre, como siempre, se metió en la Resistencia ${ }^{41}$.

En el caso de la familia de Francisca Muñoz, ante la gran afluencia de refugiados y la carencia de empleo tras la firma del Armisticio en la industria de guerra, su padre había perdido su trabajo en los talleres de aviones de guerra Breguet. Fue su madre la que ejerció de cabeza de familia desde el punto de vista económico, conservando e intensificando su trabajo en un taller de costura:

Mi madre seguía trabajando en el taller, confeccionando ya ropa civil; y también en casa para compensar el salario que mi padre había dejado de cobrar. El pago de unos atrasos por parte de la Caja de subsidios familiares había permitido la compra de una máquina de coser de ocasión; pedaleando en ella, mi madre iba a ganar, la subsistencia de la familia ${ }^{42}$.

En efecto, la costura se había convertido en una salida muy recurrida, y desarrollada desde los mismos refugios y campos, como recuerda Remedios Oliva: "yo podría hablar con la gente del pueblo, proponerles coser ropa o remendar; no tenía pretensiones, sólo quería trabajar, quizá me permitiera salir del campo y encontrar una solución para sacar a mi familia"43. En el primer exilio y en la guerra, la costura y confección a domicilio y otras tareas pertenecientes al espacio reproductivo permitieron a muchas familias subsistir en el plano económico, aunque en muchas ocasiones fue un trabajo no declarado que no era efectivo para, desde el punto de vista de las autoridades, demostrar la capacidad de mantener económicamente a la familia. De hecho, en el relato de Francisca Muñoz que mostrábamos unas líneas arriba, se denuncia también que el trabajo de su madre fue durante un tiempo "a escondidas":

Mi madre mantuvo algún tiempo su documentación en regla. Cuando la fecha de validez llegó a término, solicitó una prórroga con el apoyo de un contrato de trabajo recientemente expedido. El Servicio de la Mano de Obra Extranjera, juzgando que la situación laboral no justificaba ya el empleo de trabajadores foráneos, emitió un avis défavorable y una nota que obligaba al dueño de la empresa a licenciar inmediatamente a la interesada. Lo hizo oficialmente; mi madre fue borrada de las

\footnotetext{
41 Entrevista a Pilar Valls, realizada por P. Domínguez, México, 1984. En Domínguez Prats, Pilar: De ciudadanas a exiliadas... op. cit., p. 92.

42 Muñoz Alday, Francisca: Memorias del exilio...op. cit., pp. 123-124

43 Oliva Berenguer, Remedios: Éxodo... op. cit. pp. 23-24.
} 
listas del personal y dejó de trabajar en el taller; lo hacía a domicilio, sin que ese trabajo figurase en ningún registro ni fuese declarado a los organizamos de seguro social y de subsidios familiares ${ }^{44}$.

\section{Españolas en la tormenta de otra guerra. Supervivencia y vida cotidiana}

El tratamiento diferencial dispensado por la República Francesa a hombres y mujeres se intensificó ante el escenario de la guerra en Europa y, especialmente, desde la firma del Armisticio. Las medidas represoras de internamiento y reclusión en campos y refugios no fueron exclusivas para los hombres, así como tampoco las políticas de aprovechamiento de mano de obra a través de las CTE (Compañías de Trabajadores Extranjeros) y luego GTE (Grupos de Trabajadores Extranjeros), las cuales revelan, además, el interés por parte de las autoridades de conservar la mano de obra española que quedaba en Francia ante la movilización general. Como los extranjeros incorporados a estas estructuras realizaban generalmente "prestaciones de trabajo por las cuales no recibían un salario"45, podría parecer que las mujeres quedasen relegadas a un segundo plano, solamente relevantes para las políticas de reagrupación familiar o la atribución de pensiones si el cabeza de familia se encontraba sirviendo militarmente (incluyendo a las compañías y grupos de trabajo) a Francia. No obstante, los testimonios de las acciones de supervivencia que las mujeres protagonizaron en estos años, así como incluso de acompañamiento a las Compañías de Trabajo, demuestran de nuevo la necesidad de una nueva lectura de la vida cotidiana del exilio durante la guerra mundial.

La narración que Ana Delso hace de su convivencia con su compañero, Dioni durante su movilización en la $539^{\mathrm{a}}$ Compañía de Trabajadores Extranjeros contiene múltiples referencias a cómo ella fue forjando su inserción en la vida cotidiana francesa durante la guerra y la Ocupación. Mientras Dioni desempeña diversas tareas en la Compañía, luego Grupo de Trabajadores Extranjeros hasta que son disueltos a finales de 1941, Ana aprende a hacer punto. Con el traslado de la Compañía a Altos Alpes, y estando embarazada, complementa su pensión como mujer [tiene que decir que están casados] de un miembro de las CTE con otros recursos: "[La propietaria del caserío donde se hospedan] me vende leche y un poco de su propio pan. Le digo que sé coser y le ofrezco mis servicios. Me contrata. A cambio de mi trabajo, me alimentará. Por fin voy a comer cuando me plazca" ${ }^{\prime 46}$. Paralelamente, y para procurarse "algunos francos de más y algo de jabón, que es un artículo que escasea" ${ }^{47}$, lavará y planchará también la ropa a un sargento francés de la Compañía.

Pero lo más corriente es que las resistencias cotidianas de las mujeres españolas durante la guerra en Francia aparezcan desdibujadas en los grandes relatos heroicos que, también tardíamente, reivindican la participación de los exiliados en el nuevo conflicto bélico en clave masculina. El retrato que hace María Luis Broseta Martí de

44 Muñoz Alday, Francisca: Memorias del exilio...op. cit., pp. 124.

45 Catalan, Tiphaine: « Españoles y españolas en el centro de Francia durante la Segunda guerra mundial: trabajadores forzados y resistentes voluntarios », Laberintos: revista de estudios sobre los exilios culturales españoles, 20, 2018, p. 66.

46 Delso Atalaya, Ana: Trescientos hombres y yo : estampa de una revolución, Madrid, Fundación Anselmo Lorenzo, 1998, p. 113.

$47 \quad$ Ibid. p. 117 
su madre, Dolores, y de su "lucha obstinada para ganar la batalla interminable de lo cotidiano, contra el frío, el hambre y la miseria", sus aprendizajes de "madre coraje" "ingeniosa e infatigable" corresponde a "los gestos simples percibidos por los niños y generalmente protagonizados por las mujeres", como destaca Odette Martínez en el análisis de su testimonio ${ }^{48}$. La vida de la comunidad española exiliada continuó en la Francia en guerra y bajo la ocupación -o la tutela- nazi y las restricciones alimenticias y económicas, en las que los y las exiliadas tuvieron la "obsesión del día a día" de "ganarse la vida, alimentarse y vestirse":

la ropa, la podíamos hacer durar, recoserla o remendarla. Pero la comida era una cosa de todos los días. No bastaba con lo suministrado por las cartillas de racionamiento. En el mercado negro todo era más caro. Mi padre tenía derecho a una cartilla de tabaco, pero, como no fumaba, mi madre cambiaba los cigarrillos por azúcar o un poco de mantequilla. Toda una red proveía lo esencial y especulaba con lo que faltaba, claro está ${ }^{49}$.

Un caso particular es el de aquellas mujeres que decidieron intervenir políticamente ante la invasión nazi y engrosaron las filas de la Resistencia ${ }^{50}$-con mayúsculas- en casi todas sus modalidades. Las estrategias más extendidas fueron, precisamente las que, a pesar de su potencial político y militar, se desarrollaban en el terreno doméstico y familiar., difuminándose de nuevo su compromiso y militancia con la vida cotidiana. La categorización de tareas principales y tareas secundarias o auxiliares, desempeñadas estas segundas por la mayoría de mujeres, ha dejado la huella en el relato de lo que se ha denominado el "syndrome de la petite main" ${ }^{51}$, es decir, la modestia a la hora de recrear las acciones y roles desempeñados.

La capacidad de disimulo de estas mujeres, que no en vano habían vivido ya una guerra, les permitió ser de gran utilidad, beneficiándose precisamente de los estereotipos y atribuciones de género que representan a las mujeres como seres inofensivos. Un ejemplo son las tareas de enlace ${ }^{52}$ en las que las mujeres aprovechaban pasar desapercibidas o, incluso, la posibilidad de "hacerse la tonta", como la escena evocada por Soledad Alcón:

Un tipo me dice: 'Abra esa maleta'. Le dije: 'Mire, si usted tiene algo, me hará un gran favor, porque he perdido la llave y con la uña no puedo abrirla'. - 'Bueno, ¿Y una persona joven como usted no tiene miedo de viajar sola?'- 'Es que... dentro de

48 Martinez-Maler, Odette : “"Souvenirs d'enfance et d'exil” de María Luisa Broseta Martí. De l'intime à l’histoire: un passage par l'autobiographie », Exils et migrations ibériques au XXe siècle, 1-Témoignages d'exil entre parole et silence: regards et points de vue, 2004, p. 136.

49 Broseta Martí, María Luisa: « Recuerdos de infancia y de exilio », en Ibeas Vueltas, Nieves (coord.): Mujeres migrantes, Prensas de la Universidad de Zaragoza, 2019, p. 233.

50 Tomamos la definición elaborada en 1987 por Paula Schwartz de la "Resistencia" donde se tuvieran en cuenta más formas de participación política, específicamente aquellas menospreciadas por "femeninas", visibilizando así la importancia que tuvieron realmente las actividades llevadas a cabo por las mujeres. Schwartz, Paula: " Redefining resistance: women's activism in wartime France », en Higonnet, Margaret R. (dir.), Behind the lines: gender and the two world wars, New Haven, Yale University Press, 1987, pp. 141-153.

51 Blanc, Julien : " Résistances pionnières, reconnaissance et genre », en Douzou, Laurent y Yusta, Mercedes (coords.): La Résistance à l'épreuve du genre, Presses universitaires de Rennes, 2018, p. 60.

52 En palabras de Constanza Martínez: "[el] trabajo de enlace era de mucha responsabilidad, pero de poco relieve". En Català, Neus: De la resistencia y la deportación ... op. cit. p. 205. 
muy pocas horas ya no estaré sola'. - 'A la pícara le espera su amigo, ¿Hace mucho tiempo que no le ve?'. - 'Pues seis meses; ya estoy impaciente'. - 'Váyase, váyase. Hala y diviértase'. Llevaba dinero, instrucciones, cartillas de racionamiento. Si me abren la maleta... ${ }^{53}$.

Estos testimonios muestran cómo las mujeres exiliadas fueron capaces de servirse incluso de las tareas ligadas a los cuidados y a la maternidad social ${ }^{54}$ atribuidas a las mujeres en el discurso tradicional como su forma de contribuir al combate que se había iniciado en España y continuaba en Francia. La obtención de víveres y productos de primera necesidad para los guerrilleros, la asistencia y las labores de solidaridad, el alojamiento o la manutención de una casa en la que tener reuniones son parte de las actividades que se engloban dentro de lo "auxiliar" ${ }^{55}$, pero que fueron imprescindibles.

Además, la mayoría de estas mujeres tuvieron que compaginar su actividad resistente con un trabajo remunerado, como venían haciendo a lo largo de su exilio. Regina Arrieta manifestaba así que "en mi casa se hacían reuniones, se confeccionaban octavillas. Tenía que trabajar, criar a mi hijo, hacer la Resistencia"56. Pero también podemos considerar la Resistencia como un trabajo en sí, siguiendo el testimonio de Pilar Fidalgo:

En 1943 el "Maquis" me reclamó para que me dedicase solamente a ellos. Tenía una habitación que sirvió de "punto de apoyo" (...) No tenía ni un céntimo, solo tenía la comida, que me proporcionaban los camaradas. Solamente la comida del medio día. Para los demás gastos tuve que echar mano al poco dinero que tenía ahorrado del tiempo que había trabajado sirviendo (...)

Yo trabajaba por nada, sin dinero, pero tenía que pagar el alquiler de mi habitación todos los meses ${ }^{57}$.

Estos dos últimos testimonios citados, recogidos por Neus Català, coinciden en que se reivindican como mujeres activas, representando una "doble transgresión" 58 , de cara al orden social y político -en este caso del ocupante nazi- y de cara al orden tradicional de género. La especificidad del contexto de guerra no fue suficiente, como había pasado ya en la Guerra de España ${ }^{59}$, para la visibilización del combate de estas mujeres exiliadas, más allá de un vago reconocimiento por haber mantenido el hogar durante la ausencia masculina, como parte de su rol "natural". Salvo el caso de las viudas, cuya aceptación como "cabeza de familia" les dio una cierta

53 Ibid., p. 45.

54 Moreno Seco, Mónica « L'exil au féminin: Républicaines et Antifranquistes en France », en Vargas, Bruno (coord.) : La Seconde République espagnole en exil en France (1939-1977), Presses Universitaires de Champollion, 2008, p. 170

55 Ver, en el marco de la guerrilla antifranquista en España: Yusta Rodrigo, Mercedes: « Hombres armados y mujeres invisibles. Género y sexualidad en la guerrilla antifranquista (1936-1952) », Ayer, 110, 2018, pp. 285-310.

56 Català, Neus: De la resistencia y la deportación... op. cit. p. 54.

57 Ibid, p. 131.

58 Catherine Lacour-Astol, « L'éngagement résistant féminin. Quels marqueurs? Quels prismes? Quels révelateurs? », en Douzou, Laurent y Yusta, Mercedes (coords.): La Résistance à l'épreuve du genre ... op. cit. p. 33.

59 Luisa Carnés evoca así la participación femenina en la guerra: "Todas quieren ser útiles a su patria. Mujeres de todas las edades; mujeres de todas las regiones de España; mujeres con niños en los brazos ("Si me colocan al niño en algún lado, podré trabajar"). Esto permitiría poner en pie de guerra nuevos refuerzos masculinos". Carnés, Luisa: De Barcelona a la Bretaña francesa... op. cit. pp. 65-66. 
libertad de movimientos, incluso la presencia de las mujeres en la economía formal o como aporte principal (o único) de la familia fue vista como una realidad temporal y circunstancial de un contexto particularmente duro ${ }^{60}$. Y, el propio término de "trabajadoras de guerra" no deja de corresponder al elogio que, en ambas posguerras mundiales, se hizo al esfuerzo patriótico - a la par que extraordinario- de las mujeres que en estos contextos transgredieron circustancialmente sus roles, sociales y también laborales, pero que volverían a su lugar una vez recuperada "la normalidad".

Las relaciones con las autoridades alemanas de ocupación fueron problemáticas también para las mujeres exiliadas con una amenaza represiva constante. Los testimonios más ideologizados, en este caso desde el ámbito anarquista, evocan el temor a ser llevadas a Alemania y denuncian la utilización de la mano de obra de forma forzosa. Anita Pujol, internada en Rivesaltes en 1941 habla de cómo las famosas comisiones alemanas de contratación de voluntarios comenzaron a pasearse por los campos, para el trabajo en Alemania: "El dilema era: Alemania o España (...) Los discursos se escuchaban en silencio, y nadie respondía ni a las promesas ni a las amenazas. Pero para poder utilizar la mano de obra española, recurrieron a la fuerza, organizando expediciones en las que los refugiados eran enrolados en masa, y manu militari" ${ }^{\text {" }}$. Por su parte, Ana Delso, también a finales de 1941, cuando "el enfrentamiento gendarmería-resistencia-refractarios al STO ha comenzado ya o está a punto de comenzar" ${ }^{62}$, narra cómo tuvo que pasar por esta tentación:

Un sábado por la mañana, esta mujer [una supuesta asistente social] se presenta en mi casa y me dice que como vivo en muy malas condiciones y la asignación militar que recibo no me basta, está en posición de encontrarme un lugar donde seremos mejor tratadas la niña y yo. Me repite su oferta en varias ocasiones con mucha insistencia. Me figuro a dónde quiere llegar. Le digo que realizo en casa algunos trabajos de costura para la señora Francou, una modista de Corps, y además remiendo ropa para algunas mujeres a cambio de unos francos, un poco de comida o un poco de carbón. Ante su celo, llego a la conclusión de que hay una verdadera falta de mano de obra en Alemania para hacer funcionar las industrias de guerra. Sé además que hasta los niños alemanes son obligados a trabajar en ellas. Después de que se marcha, no dejo de preocuparme ${ }^{63}$.

La atribución del estatus de refugiado en marzo de 1945 implica un nuevo contexto y discurso. Así, la reconstrucción económica y social de la Francia de posguerra requirió nuevos esfuerzos de la parte de las refugiadas españolas. Estas tuvieron que hacer frente no solo a su propia estabilización e integración en la sociedad francesa sino que debieron cumplir los roles que en tanto que mujeres y refugiadas españolas tendrían asignados. Las fuentes testimoniales demuestran que, a pesar de la adquisición del estatus jurídico de Refugiadas Políticas, el fin de las persecuciones y la regularización de su situación en el pais, la mayoría de nuestras protagonistas siguieron trabajando y, además, desarrollando el mismo tipo de empleos. La estabilización

60 Pilar Domínguez Prats elabora una reflexión similar sobre el trabajo femenino en el primer exilio mexicano, el cual, con la estabilización económica de la familia, debería desaparecer: Domínguez Prats, Pilar: De ciudadanas a exiliadas, op. cit.

${ }_{61}$ Montseny, Federica : Révolutionnaires, réfugiés et résistants... op. cit. p. 68

62 Delso Atalaya, Ana: Trescientos hombres y yo... op. cit. p. 125

63 Ibid. p. 126 
y continuación de su exilio más allá del fin de la guerra mundial fueron prioridades para las mujeres españolas, también en lo económico, donde las necesidades materiales marcaron el compás ${ }^{64}$. En este sentido, la victoria aliada en la guerra no trajo consigo una redistribución de los roles de género.

Tampoco en el terreno político, lato senso. Alba Martínez ha analizado cómo en los expedientes de mujeres del fondo de Solidaridad Democrática se dibujan unas trayectorias de mujeres que subrayan sus méritos políticos, junto con las represalias que pueden sufrir o que han sufrido en España, con el fin de lograr un aval para conseguir el estatus de refugiada política. Se reivindica así el exilio femenino más allá de la reunificación familiar, en el que existieron múltiples motivaciones, como la prevención, las dificultades socio-políticas de pertenecer a una familia "roja" en la España franquista o, directamente, la huida de la represión o persecución ${ }^{65}$.

Esta investigación ha puesto en evidencia la invisibilización que sufre la mujer exiliada en el marco de la posguerra europea, no en vano en un contexto específico en el cual la maternidad y las funciones económicas de la mujer fueron especialmente subrayadas, también en la socialización antifascista ${ }^{66}$. La consolidación de la comunidad refugiada en Francia, tras las nuevas entradas en el país en los primeros años de la posguerra europea y el mencionado estatus de refugiado político, caracterizaron la senda de la integración como una de las principales preocupaciones de las exiliadas a partir de entonces. Las atribuciones domésticas de la mujer fueron, por lo tanto, un eje en la readaptación de las familias españolas en el nuevo contexto, en el que, como se ha apuntado, "tuvieron que adaptarse necesariamente al país de acogida, volviendo otra vez a su mundo privado y cotidiano, a ese tejer la vida de los demás a base de destejer la suya propia (destino común de las mujeres)" ${ }^{97}$.

Mas es precisamente la metáfora del tejido la que nos da la pista de la permanencia de importantes esfuerzos en materia laboral de las mujeres exiliadas, pues no fue hasta la segunda generación cuando existió una movilidad social ascendente. Francisca Muñoz hablaba todavía de su madre en términos del recurso a la costura como aporte económico fundamental, antes de que su familia consiguiese mudarse a Toulouse:

Diez años durante los cuales mi madre, sin descanso, había transformado en abrigos o tabardos las antas teñidas de la gente del pueblo y de los alrededores; en pantalones y chaquetas las gruesas y recias sábanas y las no menos recias camisas de lienzo que los rústicos conservaban en sus arcas de generación en generación; en blusas nuevas los vestidos viejos; en delantal de niño la bata de la madre... ${ }^{68}$.

La atención que desde el Gobierno de la República constituido en el exilio a los y las exiliadas más desfavorecidas en Francia revela, a pesar del limitado presupuesto

${ }_{64}$ Negrete Peña, Rocío: «La integración laboral de las refugiadas españolas en la posguerra francesa, o, 'les femmes ont toujours travaillé'», en Abello Güell, Teresa; Cattini, Giovanni C.; Gavín i Munté, Víctor; Ibarz Gelabert, Jordi; Santacana i Torres, Carles; Solé i Barjau, Queralt y Vives Riera, Antoni (coords): Postguerres/ Aftermaths of War, Vol. 2, Universitat de Barcelona, 2019, pp. 969-986

${ }_{65}$ Martínez Martínez, Alba : «'Pour quelles raisons avez-vous quitté l'Espagne?' De represaliadas a refugiadas políticas en la Francia de los años 40 y $50 »$, Historia Contemporánea, 59, 2019, pp. 269-305.

66 Yusta Rodrigo, Mercedes: « Construyendo el género más allá de la nación: dimensión nacional e internacional de la movilización de las mujeres antifascistas (1934-1950) », Mélanges de la Casa de Velázquez, 42, 2012, pp. 91-103.

${ }^{67}$ Alted Vigil, Alicia: « El exilio republicano español de 1939 desde la perspectiva de las mujeres », Arenal: Revista de historia de mujeres, 4-2, 1997, p. 228.

68 Muñoz Alday, Francisca: Memorias del exilio... op. cit. p. 147 
que pudieron dedicar en forma de subsidios, el seguimiento mediante fichas de identidad de la situación material y de las capacidades de cada refugiado y refugiada. La información que estas fichas, muchas veces acompañadas de cartas con peticiones evoca, no solamente unas condiciones materiales precarias para la comunidad refugiada, sino la capacidad de adaptación y las salidas para sus carencias cotidianas que mujeres, como Montserrat de Graner, buscaron:

Referente al trabajo tengo una máquina de tricoter con la que lo mismo pueden hacerse tricota de lujo que corrientes y puedo hacer también cosas muy bonitas en tricot a mano.

Si fuese posible a este Ministerio, lo que verdaderamente resolvería mi situación, sería que pudiese acordárseme un adelanto, en calidad de préstamo, para motorizar mi máquina (que por las mismas razones de salud no puedo emplear a mano) y adquirir unos quilos de lana y de algodón para poder desarrollar la confección de tricot, pues no puedo explotar dicha máquina por falta de material" ${ }^{69}$.

Es sintomático que, en la mayoría de las fichas, la ocupación de las mujeres que la rellenaron sea "sus labores". Bajo esta denominación (y en contraste con las diversas fuentes testimoniales que dan fe de la variedad de actividades realizadas por las mujeres en el exilio en el ámbito doméstico, pero con grave impacto y relevancia para la estructura familiar), encontramos todo un abanico de tareas de tipo social y económico tradicionalmente asignadas al universo femenino. La carga semántica de este término -acompañado siempre de sus-implica la pertenencia natural de estas tareas a las mujeres, pero, a su vez, la sustitución que encontramos en las fichas entre "sus labores" por "sin profesión" denota la falta de valorización o, en todo caso, la asunción como "complementarias" del trabajo de las mujeres, sobre todo si se desarrollaba en el marco del hogar.

A pesar de estas asignaciones, la vida cotidiana evocada por las mujeres en el exilio muestra diversas situaciones de gran precariedad en las que es ella la que se hace cargo de la familia:

soy una mujer que desgraciadamente me encuentro toda sola con mi suegra y mis dos hijos mi marido lo he perdido en las cárceles de España- los hijos los tengo aquí en la escuela provisional y no me ganan nada (...) Tengo dos hijos en una edad 17 el mayor y el otro 15 que es la edad que les conviene más alimento yo no tengo nada. Qué triste es por una madre cuando les quiere dar y no tiene... ${ }^{70}$

Sería interesante analizar el discurso de la domesticidad de estos años desde un punto de vista transnacional en relación con la realidad vivida por las mujeres en la España franquista, recluidas por el discurso político en "sus labores"71. Igualmente, en el marco de las resistencias femeninas al franquismo, el mantenimiento de la fa-

69 «Carta de Montserrat de Graner Pons, Paris, 14/1/1948». Fondos del Ministerio de Emigración, Declaración para Censo de Asistencia Social: EMIG/ 131.3. Archivo del Gobierno de la República en el Exilio, Fundación Universitaria Española.

70 «Carta de María Calbet, Pau, 15/3/1948». Fondos del Ministerio de Emigración, Declaración para Censo de Asistencia Social: EMIG/ 130.3. Archivo del Gobierno de la República en el Exilio, Fundación Universitaria Española.

71 Sánchez Sánchez, Pura: Individuas de dudosa moral... op. cit., p. 65 y ss. 
milia también requirió una intensa dedicación a las tareas cotidianas del hogar como base para la realización de la actividad política ${ }^{72}$. Es así además como vemos, que bajo este término asociado a toda actividad de las mujeres, incluso aquellas abierta y reconocidamente politizadas, subyace la confesión de Irene Falcón ${ }^{73}$ de la doble jornada militante que debían desempeñar en el espacio político y el "doméstico" ante la ausencia de los hombres en este segundo.

\section{Conclusiones}

La imposición de una división de tareas según el género marcó las trayectorias de las mujeres exiliadas, desde aquellas englobadas en "el común" a aquellas cuya resistencia participación política tuvo más luz. Ángeles Egido ${ }^{74}$ ha subrayado la potencialidad del estudio del exilio femenino como "otra forma de represión" ejercida en forma de huida indiscriminada, y que generan al otro lado de la frontera "otra forma de compromiso". Otras formas que son hechos diferenciales basadas en la bicategorización de la sociedad que supone el género.

Como hemos podido observar, las trayectorias de las mujeres exiliadas en Francia, si bien pueden resumirse en muchas ocasiones como una lucha contra gigantes (el franquismo, el fascismo, el patriarcado), muestran una evolución y un abanico de comportamientos y actitudes. Los diferentes grados de desarrollo y movilización en el ámbito personal, familiar y público a lo largo de su exilio denotan esta variedad de experiencias, pero también un amplio grado de adaptación y de movilización de recursos. Las resistencias cotidianas ante la política de acogida francesa, el enfrentamiento a lo que consideraban injusticias, la adopción de nuevos roles familiares y profesionales, el ejercicio de liderazgo como "cabezas de familia", la participación -solamente poco a poco reconocida- en la resistencia antifascista y la asunción de un papel de "hormiguita" cuando fue necesario son algunas de las capacidades camaleónicas que estas mujeres demostraron tener.

Por lo tanto, adentrarse en la historización del exilio femenino supone tener en cuenta las agencias y resistencias, el ejercicio activo de su calidad de exiliada republicana, heredera de la memoria de la Segunda República y de la guerra en los diversos escenarios, y el tejido de su propio destino. Sin embargo, estas trayectorias han tenido que convivir con un rol de víctima y de acompañante asignado por las autoridades francesas, pero también por los organismos de ayuda con los que las exiliadas republicanas mantuvieron unas peculiares relaciones de poder, y que se han reproducido en parte en la historia y memoria del exilio republicano ${ }^{75}$.

En concreto, el discurso de la domesticidad marcó profundamente estas trayectorias y es indispensable para entender el proceso de invisibilización por el que muchas de sus actividades y tareas pasaron. Ellas aseguraron la intendencia material, los cui-

72 Cabrero Blanco, Claudia: « Tejiendo las redes de la democracia: Resistencias cotidianas de las mujeres durante la dictadura franquista » en Yusta, Mercedes y Peiró, Ignacio: Heterodoxas, guerrilleras y ciudadanas. Resistencias femeninas en la España moderna y contemporánea, Zaragoza, Institución Fernando el Católico, 2015, pp. 197-217.

73 Falcón, Irene: Asalto a los cielos: mi vida junto a Pasionaria, Madrid, Temas de Hoy, 1996, p. 207 y ss.

74 Egido León, Ángeles: « Mujer y exilio: otra forma de represión, otra forma de compromiso. la memoria en la red », Migraciones y exilios, 17, 2018.

75 Jelin, Elizabeth: Los trabajos de la memoria... op. cit. p. 100 y ss. 
dados, y su trabajo fue indispensable tanto en el terreno familiar como el social y el económico. La reclusión al campo de los cuidados y de la economía reproductiva, el espectro de la maternidad social, y la despolitización de lo cotidiano han contribuido a la marginalidad de la experiencia femenina en los numerosos estudios del exilio republicano. Solamente el rescate de testimonios orales y escritos y la relectura de la documentación existente desde otro punto de vista, acompañada por un "cuestionamiento de paradigmas obsoletos" $" 76$ permiten integrar las múltiples realidades de las mujeres exiliadas en Francia en la elaboración de un discurso histórico del exilio en su conjunto y en toda su complejidad.

\section{Referencias bibliográficas}

Adámez Castro, Guadalupe: Gritos de papel: Las cartas de súplica del exilio español, Granada, Comares, 2017.

Aguado, Ana: " Memoria de la Guerra Civil e identidades femeninas antifranquistas », Amnis. Revue de civilisation contemporaine Europes/Amériques, 2, 2011, DOI: 10.4000/ amnis.1508; URL: http://journals.openedition.org/amnis/1508

Alted Vigil, Alicia: « El paso de frontera como ruptura en las mujeres exiliadas », en Almela Boix, Margarita; García Lorenzo, María Magdalena; Guzmán García, Helena; Sanfilippo, Marina (coords.): Mujeres en la frontera, Madrid, Universidad Nacional de Educación a Distancia, 2013, pp. 39-52.

Alted Vigil, Alicia: « El exilio republicano español de 1939 desde la perspectiva de las mujeres », Arenal: Revista de historia de mujeres, 4-2, 1997, pp.. 223-238.

Berenguer, Sara: Femmes d'Espagne en lutte: Le courage anonyme au quotidien, de la guerre civile à l'exil, Lyon, Atelier de création libertaire, 2011.

Blanc, Julien: " Résistances pionnières, reconnaissance et genre », en Douzou, Laurent y Yusta, Mercedes (coords.): La Résistance à l'épreuve du genre, Presses universitaires de Rennes, 2018, pp. 51-68.

Bravo, Blanca (coord.): Nuevas Raices: Testimonios de Mujeres Españolas en el Exilio, México, Editorial Joaquín Mortiz, 1993. Disponible en http://www.cervantesvirtual.com/ obra/nuevas-raices-testimonios-de-mujeres-espanolas-en-el-exilio--0/

Broseta Martí, María Luisa: « Recuerdos de infancia y de exilio »,en Ibeas Vueltas, Nieves (coord.): Mujeres migrantes, Prensas de la Universidad de Zaragoza, 2019, pp. 175-252.

Cabrero Blanco, Claudia: « Tejiendo las redes de la democracia: Resistencias cotidianas de las mujeres durante la dictadura franquista » en Yusta, Mercedes y Peiró, Ignacio: Heterodoxas, guerrilleras y ciudadanas. Resistencias femeninas en la España moderna y contemporánea, Zaragoza, Institución Fernando el Católico, 2015, pp. 197-217. URL: https://ifc.dpz.es/recursos/publicaciones/34/28/10cabrero.pdf.

Carnés, Luisa: De Barcelona a la Bretaña francesa. Memorias, Biblioteca del exilio., Barcelona, Renacimiento, 2014.

Català, Neus: De la resistencia y la deportación. 50 testimonios de mujeres españolas, Barcelona, Adgena, 1984.

Catalan, Tiphaine: « Españoles y españolas en el centro de Francia durante la Segunda guerra mundial: trabajadores forzados y resistentes voluntarios "), Laberintos: revista de estudios

76 de Hoyos Puente, Jorge: « Las mujeres exiliadas...» art. cit, p. 39. 
sobre los exilios culturales españoles, 20, 2018, pp. 63-78. Número completo disponible en: https://bivaldi.gva.es/es/catalogo_imagenes/grupo.cmd?path=1022500

Delso Atalaya, Ana: Trescientos hombres y yo : estampa de una revolución, Madrid, Fundación Anselmo Lorenzo, 1998.

Domínguez Prats, Pilar: De ciudadanas a exiliadas: un estudio sobre las republicanas españolas en México, Madrid, Cinca, 2009.

Dreyfus Armand, Geneviève: L'exil des républicains espagnols en France: de la Guerre civile à la mort de Franco, Paris, Albin Michel, 1999.

Egido León, Ángeles: « Mujer y exilio: otra forma de represión, otra forma de compromiso. la memoria en la red », Migraciones y exilios, 17, 2018.

Falcón, Irene: Asalto a los cielos: mi vida junto a Pasionaria, Madrid, Temas de Hoy, 1996.

Groppo, Bruno: «La notion de réfugié au XXe siècle », Exils et migrations ibériques au XXe siècle, 2-7, 1999, pp. 165-178, DOI: https://doi.org/10.3406/emixx.1999.1035; URL : www.persee.fr/doc/emixx_1245-2300_1999_num_2_7_1035

Carmen de la Guardia: "Maestras republicanas españolas en el exilio" en Sánchez de Madariaga, Elena (coord.): Las maestras de la República, Madrid, Los Libros de la Catarata, 2012, pp. 184-235

de Hoyos Puente, Jorge: « Las mujeres exiliadas con la configuración de la identidad cultural y política de los refugiados españoles en México », Ubi sunt? Revista de Historia, 0-27, 2012, pp. 28-40.

Jelin, Elizabeth: Los trabajos de la memoria, Madrid, Siglo XXI de España Editores, 2002.

Catherine Lacour-Astol: «L'éngagement résistant féminin. Quels marqueurs? Quels prismes? Quels révelateurs? », en Douzou, Laurent y Yusta, Mercedes (coords.): La Résistance à l'épreuve du genre, Presses universitaires de Rennes, 2018, pp. 33-49.

Martínez Martínez, Alba: « Las mujeres recuerdan. Género y memoria sobre el exilio republicano en Francia (1939-1978) », Arenal: Revista de historia de mujeres, 26-2, 2019, pp. 367-398, DOI: https://dx.doi.org/10.30827/arenal.v26i2.9236; URL: https://revistaseug.ugr.es/index.php/arenal/article/view/9236

Martínez Martínez, Alba: « 'Pour quelles raisons avez-vous quitté l'Espagne?' De represaliadas a refugiadas políticas en la Francia de los años 40 y 50 », Historia Contemporánea, 59, 2019, pp. 269-305, DOI: https://doi.org/10.1387/hc.18977; URL: https://www.ehu. eus/ojs/index.php/HC/article/view/18977

Martinez-Maler, Odette: «"Souvenirs d'enfance et d'exil” de María Luisa Broseta Martí. De l'intime à l'histoire: un passage par l'autobiographie ", Exils et migrations ibériques au XXe siècle, 1-Témoignages d'exil entre parole et silence: regards et points de vue, 2004, pp. 131-148., URL : https://www.persee.fr/doc/emixx_1245-2300_2004_num_3_1_1069

Maugendre, Maëlle: «Les réfugiées espagnoles en France (1939 - 1942) : des femmes entre assujettissements et résistances » Thèse de doctorat, Université de Toulouse Mirail, Toulouse, 2013. Disponible en https://tel.archives-ouvertes.fr/tel-00961467

Merchán Tejero, Francisca (dir.): Memorias del olvido : la contribución de los republicanos españoles a la resistencia y a la liberación de Francia, Federación de Asociaciones y Centros de Emigrantes Españoles en Francia, 1996.

Mistral, Silvia: Exodo. Diario de una refugiada española, Madrid, Diario Publico, 2011.

Montseny, Federica: Révolutionnaires, réfugiés et résistants : Témoignage des républicains espagnols en France, Editions CNT-Région parisienne, 2018.

Moreno Seco, Mónica: «Las exiliadas, de acompañantes a protagonistas », Ayer, 81, 2011, pp. 265-281, URL: http://revistaayer.com/sites/default/files/articulos/81-10-ayer81_IntelectualesTransicion_Munoz.pdf 
Moreno Seco, Mónica: «L'exil au féminin: Républicaines et Antifranquistes en France », en Vargas, Bruno (coord.) : La Seconde République espagnole en exil en France (19391977), Presses Universitaires de Champollion, 2008, pp. 163-182.

Muñoz Alday, Francisca: Memorias del exilio, Barcelona, Viena, 2007.

Murillo Aced, Irene: En defensa de mi hogar y mi pan: estrategias femeninas de resistencia civil y cotidiana en la Zaragoza de posguerra, 1936-1945, Universidad de Zaragoza, 2013.

Nadal, Marie-José: « Femmes de l'exil espagnol. Formation idéologique et action politique des femmes du peuple ayant choisi de s'exiler en France en 1939 », Matériaux pour l'histoire de notre temps, 15-1, 1989, pp. 28-37, DOI : https://doi.org/10.3406/ mat.1989.401574; URL : www.persee.fr/doc/mat_0769-3206_1989_num_15_1_401574

Negrete Peña, Rocío: « La integración laboral de las refugiadas españolas en la posguerra francesa, o, 'les femmes ont toujours travaillé'», en Abello Güell, Teresa; Cattini, Giovanni C.; Gavín i Munté, Víctor; Ibarz Gelabert, Jordi; Santacana i Torres, Carles; Solé i Barjau, Queralt y Vives Riera, Antoni (coords): Postguerres/ Aftermaths of War, Vol. 2, Universitat de Barcelona, 2019, pp. 969-986

Negrete Peña, Rocío: « Cuando las exiliadas dejaron de ser des bouches inutiles. Españolas en Francia e inserción laboral: 1939-1940 », en Moreno Seco, Mónica; Fernández-Sirvent, Rafael y Gutiérrez Lloret, Rosa Ana (coords.): Del siglo XIX al XXI. Tendencias y debates. XIV Congreso Asociación de Historia Contemporánea, 20-22 septiembre 2018, Alicante, 2019, pp. 1454-1466.

Oliva Berenguer, Remedios: Éxodo: Del campo de Argelès a la maternidad de Elna, Barcelona, Viena, 2006.

Rodrigo, Antonina: Mujer y exilio, 1939, Madrid, Compañía Literaria, 1999.

Sánchez Sánchez, Pura: Individuas de dudosa moral: la represión de las mujeres en Andalucía (1936-1958), Barcelona, Crítica, 2009.

Schwartz, Paula: « Redefining resistance: women's activism in wartime France », en Higonnet, Margaret R. (dir.), Behind the lines: gender and the two world wars, New Haven, Yale University Press, 1987, pp. 141-153.

Röwekamp, Marion: « Myth of Equality? Professional Life of Spanish Republican Women in Exile in Mexico », iMex Revista. México Interdisciplinario, 5-3, 2013, pp. 86 108, URL: https://www.imex-revista.com/wp-content/uploads/Myths-of-equality_MR.pdf

Tuban, Grégory: Camps d'étrangers : le contrôle des réfugiés venus d'Espagne (1939-1944), París, Nouveau Monde éditions, 2018.

Vázquez Laba, Vanesa; Rísquez Buonaffina, Mariela; Perazzolo, Romina y Giménez Mercado, Claudia: «Resistencias desde los márgenes: la experiencia migratoria de las mujeres como forma de agencia social», Revista de estudios de género: La ventana, 5-40, 2014, pp. 59-87, URL: http://www.scielo.org.mx/scielo.php?script=sci_arttext\&pid $=$ S1405-94362014000200004

Yusta Rodrigo, Mercedes: « Hombres armados y mujeres invisibles. Género y sexualidad en la guerrilla antifranquista (1936-1952) », Ayer, 110, 2018, pp. 285-310, URL: http:// revistaayer.com/articulo/1289

Yusta Rodrigo, Mercedes: « Construyendo el género más allá de la nación: dimensión nacional e internacional de la movilización de las mujeres antifascistas (1934-1950) », Mélanges de la Casa de Velázquez, 42, 2012, pp. 91-103, DOI : 10.4000/mcv.4597; URL: http://journals.openedition.org/mcv/4597 